effective in starting people to think about it, but can never suffice to show what policy should be adopted. To demonstrate what ought to be done is one thing; but to show how to do it is, as all practical men know, a very different and generally a much more difficult thing. We hope, therefore, that if our naval friends, for whose professional ability Science entertains the highest respect, really desire the transfer, they will present such a detailed plan of proceeding from beginning to end, that every one shall be able to understand and criticise it. Until they do this, they must not expect to excite congress to action.

We may add one general consideration. A considerable number of naval officers are actually engaged in coast-survey work. Is not their work as effectively performed under the present system as it would be if the navy department had charge of it? What would the officers themselves, or the navy at large, gain by the transier? We are aware that Secretary Chandler considered it a very great hardship that officers should be removed from the immediate control of the department to which they belong. But where does the real evil come in? These questions must be answered, and the public benefit to be gained by the change must be made clear, before the project can receive the really effective support of scientific men. The latter are not disposed to prejudge the question, but before supporting the measure they want to be satisfied of its practical advisability ; and this can be done only by the advocates of the change fully considering such questions as those above suggested.

\section{COMPOSITE PORTRAITS OF AMERICAN INDIANS.}

ON the plate accompanying this number is given, so far as known, the first presentation of composite portraits taken of North American Indians.

No. 1 is of three full-blood Dakota or Sioux young women belonging to the band commonly known as the Brule, and living at the Crow Creek agency, Dakota territory. Their ages range from nineteen to twenty-three years. Their average height is five feet six inches and a half; their average weight, a hundred and forty-one pounds. This composite is made from photographs taken on the same day and in rapid succession. On the same afternoon, composite No. 2 was taken from the same persons, each one sitting her allotted seconds before the camera. In No. 1 and No. 2 the order of the faces is identical, and care was exercised to try and procure similar results in the portrait; but, as will be observed, the composites are different. The controlling face in No. 1 is given in picture No. 3, which was the first photograph to be exposed in making up composite No. 1. The dominant face in No. 2 is given in picture No. 4. It belonged to the last sitter, and her photograph was the last one exposed in making composite No. 1. In two composites similarly made, of Omaha women, the one from sitters varies in a like manner from the one made up from photographs, only in a different order. In the one from life the broad face of the last sitter controls the composite, and in the other the long face of the first photograph influences the picture. This variation of composites made from the same faces - one taken from life, the other from photographs - is mentioned for what it may be worth.

A composite of Omaha men, a cognate tribe, differs but little from a Dakota composite, except in the eyes. In the Omaha composite the eyes are larger and fuller. The height and breadth of head, the strong but not unduly heavy lower face, are noticeable in both Omahas and Dakotas. A composite of Omaha women does not differ in any marked manner from the Dakota portrait. In both the pictures of the women, there is to be observed a similar variation between the female and the male of the same tribe, notably in the shape of the head, and the greater prominence, proportionally, of the cheek-bones in the women's faces.

It is premature to judge of the value of composite portraits. They are certainly curious and interesting, and many points will occur to the observer of these Indian faces. In a general way, they seem to confirm the results of a close study of the home-life and the various customs, including the most savage rites of war and religion, made by the writer among this family of Indian tribes, by showing them to be a people, intellectual rather than brutal, unawakened rather than degraded. The portraits indicate the stamp of tribal fixity, and reveal the unconsciousness within the individual of the analytical powers of mind by which man masters nature, - a peculiarity which is the key to much in Indian sociology and religion.

The writer is indebted to Mr. Jenness Richardson of Washington, D.C., for the making of the composites. Alice C. Fletcher.

\section{GEOGRAPHICAL NOTES.}

Siberian trade-routes. - The practical failure of the route by sea has stimulated the search for routes of inland communication between Russia and Siberia. The latest investigations are those be- 


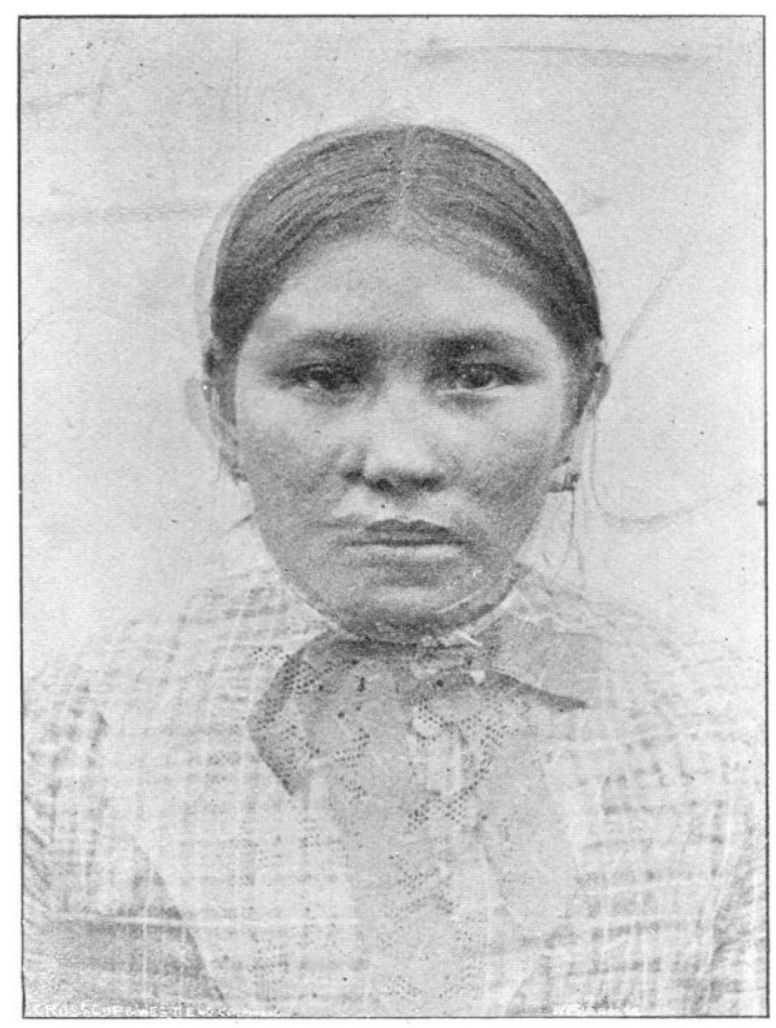

Fig. 1. - Composite from pHotcgraphs.

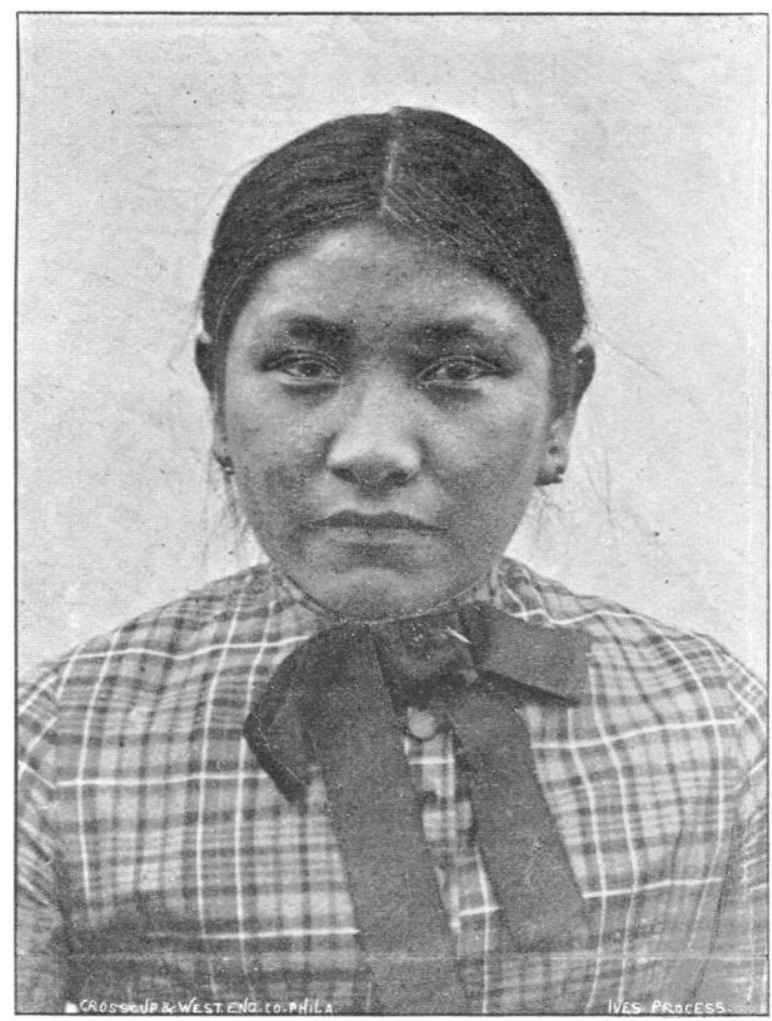

Fig. 3. - Ruling face in Fig. 1.

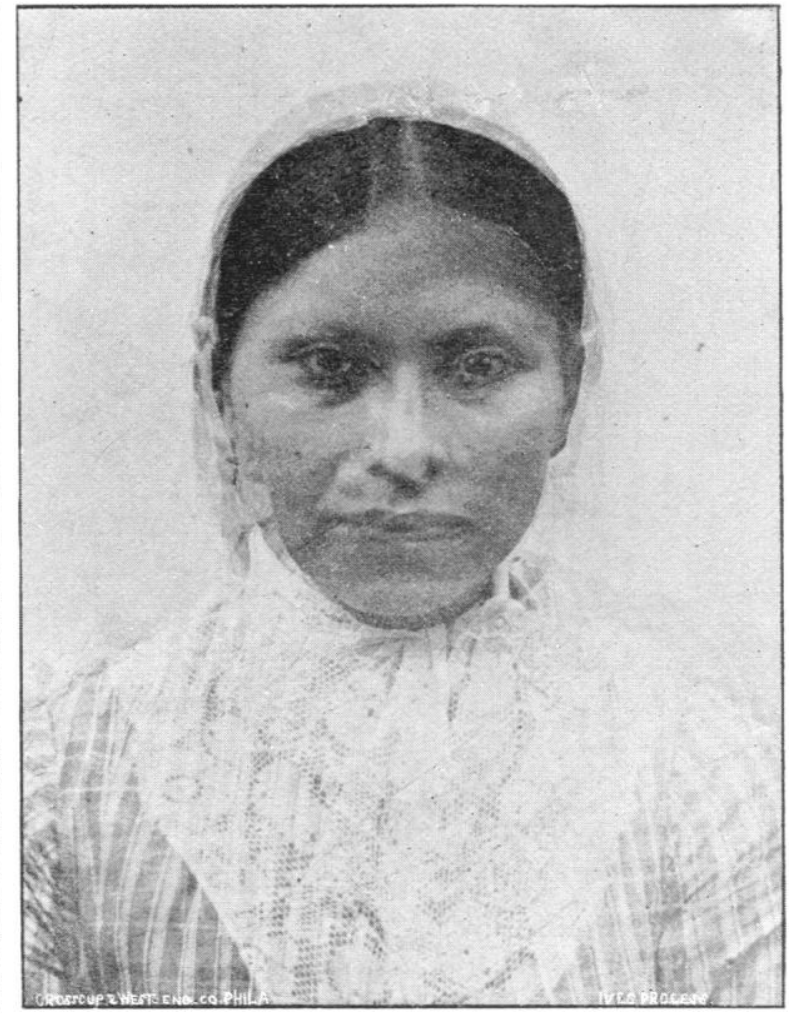

Fia. 2 - Composite From direct sittings.

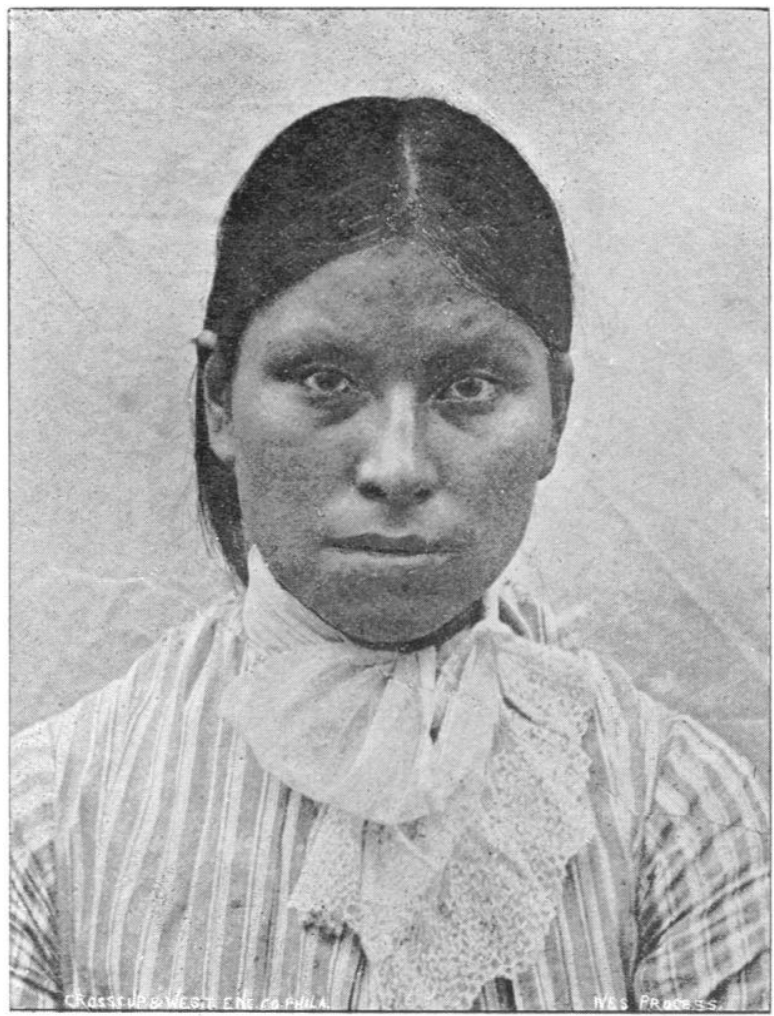

Fig. 4. - RUlixg fack in fig. 2. 